\title{
Effectiveness of counseling at primary health facilities: Level of knowledge of antenatal attendee and their attitude on Prevention of Mother to Child Transmission of HIV in primary health facilities in Dar es salaam, Tanzania.
}

\author{
*Wangwe PJT ${ }^{1,2}$, Nyasinde $\mathrm{M}^{2}$, Charles DSK ${ }^{1,2}$
}

1. Department of Obstetrics and Gynaecology, Muhimbili University of Health and Allied Sciences, P.O.BOX 65117, Dar-es Salaam, Tanzania.

2. Department of Obstetrics and Gynaecology, Muhimbili National Hospital, Dar es Salaam, Tanzania

\begin{abstract} interventions. edge gained and attitude changes towards PMTCT. of one's serostatus.

\section{Introduction}

More than $90 \%$ of the children living with HIV worldwide, majority are infected through mother to child transmission (MTCT) acquired during pregnancy, labour and through breastfeeding ${ }^{1-3}$. In the year 2009 about 400,000 children below 15 years were infected with $\mathrm{HIV}^{4}$ The cumulative likelihood chance that the baby born to HIV-infected mother will acquire HIV is $20-45 \%$ without any intervention if breastfeeding is prolonged to 2 years ${ }^{1}$. In high-income countries, MTCT rates of less than $2 \%$ have been reported thanks to routine testing, accessibility to Ant Retroviral (ARVs) prophylaxis and safe use of breast milk substitutes ${ }^{5,6}$. There is an increase in mortality related to HIV/AIDS in women and children aged below 5 years, creating
\end{abstract}

Background: Children living with HIV worldwide majority are infected through mother to child transmission of HIV (MTCT) acquired during pregnancy. Knowledge, attitude and behavioral changes are pivot tools towards success of any

Objectives: To determine the effectiveness of counseling on HIV done in primary health facilities (PHF), level of knowl-

Methods: A cross sectional study assessing pregnant women's knowledge and their attitude towards PMTCT was conducted in Temeke district from October 2010 to Jan 2011 using a structured questionnaire.

Results: A total of 383 antenatal attendees were referred to Temeke district for management after counselled and tested for HIV in PHFs. Majority (86.9\%) had primary education and good knowledge on MTCT. Correct timing of ARVs prophylaxis $(15.7 \%)$ as preventive measures for MTCT was poor. Education and employment were associated with good knowledge on MTCT of HIV. Women had positive attitudes towards HIV counseling and testing, but stigma was a barrier to disclosure

Conclusion: There is knowledge gap in routine PMTCT counseling among antenatal attendees in our PHFs. Effective counseling on PMTCT in the PHFs will bridge the identified knowledge gap and help in reduction of pediatric HIV. African Health Sciences 2014;14(1): 150-156 http:/ /dx.doi.org/10.4314/ahs.v14i1.23

\section{Corresponding author: \\ Peter JT Wangwe \\ Department of Obstetrics and Gynecology \\ Muhimbili University of Health and Allied \\ Sciences (MUHAS) \\ P. O. Box 65117 Dar es Salaam, Tanzania \\ Tel: +255784450340 \\ Email:drwangwe@yahoo.com}

approximately 1 million children orphaned within the $\operatorname{country}^{7,8}$. The health belief model describes health behaviour as a function of individual's socio-demographic characteristics, knowledge and attitudes. It has a positive effect in behavioural changes but seems to have little impact in HIV/AIDS due to confounder factors on people's decisions regarding their health behaviours that influence their decision to change which was beyond the scope of this study ${ }^{9}$.

Knowledge and attitude on PMTCT of HIV has an impact on the practice of HIV prevention, counseling and testing, adherence to medication and attitude towards PMTCT interventions. This study examines the effectiveness of counseling on HIV and PMTCT done in PHFs and level of knowledge gained and attitude change towards PMTCT.

\section{Methods}

A cross sectional study was conducted from October 2010 to Jan 2011 in Temeke district hospital, Dar es Salaam. Temeke district has 3 divisions and 24 wards covering an area of 656 square Kilometers. According to 2002 Census with an estimated annual population increase rate of $4.3 \%$ the population was projected to be 964,320. The district has a total of 109 PHFs which of- 
fer reproductive and child health (RCH) services including PMTCT which is provider initiated. The RCH clinic at the district Hospital is the first referral level which receives patients from PHF in the district. These clients has been counseled and tested for HIV in the PHFs and are referred for various reasons including investigations for CD4+ count, ARVs treatment and other obstetric complications.

During antenatal care a group pre-test education is given where information about HIV/AIDS infection, HIV transmission and PMTCT, benefits of HIV testing for pregnant women, testing process and confidentiality, partner testing and disclosure, discordance couples, meaning and effects of results, safer sex and possibility of getting ARVs prophylaxis for those found HIV infected or anti-retroviral therapy(ARTs) if eligible. Time is provided for discussion and questions. Thereafter in a private room HIV test is performed and individual post test counseling is given according to test result. For HIV negative client discussion is on partner testing, safer sex and risk reduction and retesting after 3 months, exclusive breast feeding up to 6 months then complementary feeding while continuing breast feeding for 2 years. In HIV infected individuals in addition to post test counseling, they are clinically staged and CD4 testing done to determine their eligibility for ARTs. Infant feeding counseling including replacement feeding if affordable, feasible, acceptable, sustainable and safe(AFASS) or exclusive breast feeding for 6 months if not AFASS and transit to complementary feeding up to 12 months is given. Counseling is also given on infant ARVs prophylaxis and HIV early infant diagnosis (HEID) according to the national PMTCT guidelines. Temeke RCH clinic has four offices; administration, registration, family planning and consultation. Clients rest in a waiting bay before entering in either of the above mentioned office.

\section{Data collection}

The Swahili questionnaire was used to collect information. This was translated from English to Swahili and then back to English. The questionnaire was pre-tested at Muhimbili National hospital clinics. An interview was conducted by research assistants, two nurse counselors and one medical officer. All referred antenatal attendees in Temeke hospital who had been counseled on PMTCT were eligible for the study. PMTCT counseling and testing was given to women who were not tested for HIV before but were not included in the analysis. The study participants were informed about the aim of the study and its importance. This was followed by signing informed written consent before the interview. The interview took about 20 minutes per client, and this was done after the client's consultation with the physician was over.

Knowledge was assessed using participant's responses. The five questions used had a total score of 14 points. Each correct response scored 1 and a wrong response scored zero. The basic knowledge on HIV transmission was assessed on: unsafe blood transfusion, sharing sharps with an infected person, MTCT and unprotected sexual intercourse. The risk factors on HIV transmission had a total score of 6 points -unprotected sexual intercourse with an infected person, multiple sexual partners, sexually transmitted infection and intravenous drug abuse. Preventive measures for HIV transmission scored 3 points - abstinence, being faithful to one sexual partner and condom use.

The responses were summed up and a total score was obtained for each respondent. The mean score was calculated and score was put in a scale of good, moderate and poor basic knowledge on HIV/AIDS represented by more than10, 7-9 and less than 6 respectively.

A total of 26 points assessed respondents' knowledge on MTCT during pregnancy, delivery and breastfeeding. The score were grouped into more than 20, 15-19 and less than 14 points indicating good, moderate and poor knowledge respectively.

Attitude was assessed by 8 questions which had a total score of 40 points. These were put on likert's scale and respondents were provided with statements indicating the extent to which they agree with those statements (strongly agree 5, agree 4, have no opinion 3, disagree 2 or strongly disagree 1 ). The responses were summed up and a total score was obtained for each respondent. The mean score was calculated and those who scored above the mean had a positive attitude whereas those who scored below the mean had a negative attitude towards PMTCT strategies. The score range was between 8 and 40.

Data was analyzed using SPSS version 17.0.The Chisquare test was used to measure the strength of associations between variables, a p-value

\section{Ethical issues}

Ethical approval for this research was obtained from MUHAS Ethical Research Committee and the permis- 
sion to conduct the study was obtained from Temeke District Medical Officer. All study participants provided informed consent prior to enrolment into the study.

\section{Results.}

During the study period, a total of 383 pregnant women were referred to Temeke hospital $\mathrm{RCH}$ clinic. Twenty three eligible pregnent women were excluded from the study because they were in critical conditions and could not be interviewed. Three hundred and sixty (93.9\%) were interviewed and 9 were excluded from analysis because questionnaires had significant missing data

Table 1. Knowledge on PMTCT of HIV $(n=351)$

\begin{tabular}{|c|c|}
\hline What are the ways of PMTCT? & Yes n $(\%)$ \\
\hline ARV in pregnancy & $280(79.8)$ \\
\hline $\begin{array}{l}\text { Caesarian delivery } \\
\text { ARV to the newborn } \\
\text { I don't remember }\end{array}$ & $\begin{array}{l}44(12.5) \\
150(42.7) \\
42(12.0)\end{array}$ \\
\hline Are there medications to reduce MTCT? & $331(94.3)$ \\
\hline $\begin{array}{l}\text { When does all HIV positive pregnant women } \\
\text { supposed to start ARV prophylaxis? } \\
\text { First trimester }\end{array}$ & $45(12.8)$ \\
\hline Second trimester & $163(46.4)$ \\
\hline Third trimester & $78(22.2)$ \\
\hline I don't remember & $55(15.7)$ \\
\hline $\begin{array}{l}\text { If a pregnant woman is infected with HIV } \\
\text { Can MTCT occur? }\end{array}$ & $338(96.3)$ \\
\hline $\begin{array}{l}\text { When does MTCT occur? } \\
\text { Pregnancy }\end{array}$ & $172(49.0)$ \\
\hline Vaginal delivery & $299(85.2)$ \\
\hline Breastfeeding & $313(89.2)$ \\
\hline $\begin{array}{l}\text { Breastfeeding(BF) knowledge on the risks } \\
\text { that increase MTCT } \\
\text { BF as the mother wishes }\end{array}$ & $5(1.4)$ \\
\hline BF for $6 \mathrm{~m}$ exclusively & $345(98.3)$ \\
\hline Infant formula / cow's milk & $151(43.0)$ \\
\hline
\end{tabular}

* There were multiple responses in some of the questions 


\begin{tabular}{|c|c|c|c|c|}
\hline $\begin{array}{l}\text { Sociodemographic } \\
\text { characteristics }\end{array}$ & $\begin{array}{l}\text { Good } \\
(\mathrm{N}, \%)\end{array}$ & $\begin{array}{l}\text { Knowledge } \\
\text { Moderate } \\
(\mathbf{N}, \%)\end{array}$ & $\begin{array}{l}\text { level Poor } \\
\text { (N,\%) }\end{array}$ & $\mathrm{p}$ value \\
\hline $\begin{array}{l}\text { Age(yrs) } \\
<19 \text { yrs }\end{array}$ & $6(11.8)$ & $19(37.3)$ & $26(51.0)$ & \multirow{3}{*}{$P=0.009$} \\
\hline $20-34$ & $35(14.0)$ & $132(52.8)$ & $83(33.2)$ & \\
\hline$>35+$ & $14(28.0)$ & $24(48.0)$ & $12(24.0)$ & \\
\hline $\begin{array}{l}\text { Education Level } \\
\text { No formal education }\end{array}$ & $0(0.0)$ & $2(18.2)$ & $9(81.8)$ & \multirow[b]{2}{*}{$P=0.000$} \\
\hline $\begin{array}{l}\text { Primary education } \\
\text { Secondary education }\end{array}$ & $\begin{array}{l}40(13.1) \\
15(42.9)\end{array}$ & $\begin{array}{l}158(51.8) \\
15(42.9)\end{array}$ & $\begin{array}{l}107(35.1) \\
5(14.3)\end{array}$ & \\
\hline $\begin{array}{l}\text { Current Marital Status } \\
\text { Single }\end{array}$ & $11(11.6)$ & $38(40.0)$ & $46(48.4)$ & \multirow[b]{3}{*}{$P=0.027$} \\
\hline Married & $42(17.8)$ & $127(51.3)$ & $73(30.9)$ & \\
\hline Divorced/widow & $2(20.0)$ & $10(70.0)$ & $2(10.0)$ & \\
\hline Occupation & & & & \multirow{5}{*}{$P=0.000$} \\
\hline Employed & $12(46.2)$ & $10(38.5)$ & $4(15.4)$ & \\
\hline Bussiness & $16(13.0)$ & $66(53.7)$ & $41(33.3)$ & \\
\hline Housewife & $25(14.0)$ & $92(53.4)$ & $61(34.3)$ & \\
\hline Informal employment & $2(8.3)$ & $7(29.2)$ & $15(62.5)$ & \\
\hline
\end{tabular}

Table 3: Participants responses on attitude questions ( $\mathrm{n}=351$ )

\begin{tabular}{|c|c|c|c|}
\hline \multirow{2}{*}{ Statement } & \multicolumn{3}{|l|}{ Response } \\
\hline & Agree $(\mathrm{N}, \%)$ & $\begin{array}{l}\text { Disagree }(\mathrm{N}, \\
\%)\end{array}$ & $\begin{array}{l}\text { No opinion }(\mathrm{N}, \\
\%)\end{array}$ \\
\hline $\begin{array}{l}\text { Do you think it is important } \\
\text { that every pregnant woman } \\
\text { gets tested for HIV? }\end{array}$ & 349 (99.4) & $2(0.6)$ & $0(0)$ \\
\hline $\begin{array}{l}\text { Once you are HIV positive, } \\
\text { you should not get } \\
\text { pregnant. }\end{array}$ & $206(58.7)$ & 118 (33.6) & $27(7.7)$ \\
\hline $\begin{array}{l}\text { Using protective gears for } \\
\text { safe sex (condoms) during } \\
\text { pregnancy/ BF reduces }\end{array}$ & $166(47.3)$ & 101 (28.8) & $84(23.9)$ \\
\hline $\begin{array}{l}\text { MTCT. } \\
\text { Some women BF beyond } \\
6 \mathrm{~m} \text { due to fear of stigma. }\end{array}$ & 301 (85.8) & $46(13.1)$ & $4(1.1)$ \\
\hline $\begin{array}{l}\text { Somewomen BFbeyond } 6 \mathrm{~m} \\
\text { due to fear of disclosure }\end{array}$ & $339(96.6)$ & $3(0.8)$ & $9(2.6)$ \\
\hline $\begin{array}{l}\text { Somewomen BFbeyond } 6 \mathrm{~m} \\
\text { due to lack of education }\end{array}$ & 291 (82.9) & $20(5.7)$ & 39 (11.1) \\
\hline $\begin{array}{l}{ }^{*} \text { think my family will } \\
\text { support me on the choice } \\
\text { of feeding the baby }(\mathrm{HIV}+)\end{array}$ & $56(48.7)$ & $58(51.3)$ & $0(0 \%)$ \\
\hline $\begin{array}{l}\text { Do you support National } \\
\text { PMTCT interventions? }\end{array}$ & $351(100)$ & $0(0 \%)$ & $0(0 \%)$ \\
\hline
\end{tabular}

*Includes only HIV positive respondents. 


\section{Discussion}

Effective implementation of any intervention depends on knowlege and attitudes of the targeted population . PMTCT of HIV has the potential to eliminate pediatric HIV in sub Saharan Africa, the area with high burden of HIV/AIDS worldwide. The study found that $20 \%$ and $62 \%$ of respondents who received counselling on PMTCT had good to moderate basic knowledge about HIV/AIDS. Antenatal counselling for HIV is routinely conducted in most of the Sub Saharan countries including Tanzania.Due to dynamic changes of HIV knowledge and in particular PMTCT, this finding was satisfactory compared to the study done in Northern Tanzania, Ethiopia and in Nigeria ${ }^{10-12}$ where the level of knowledge was found to be high.

Majority of the respondents $96.3 \%$ were aware of the possibility of an infected pregnant woman transmitting infection to her unborn child. Breastfeeding ranked high followed by intrapartum and prenatal period on timing at which MTCT is most likely to occurs.This finding is not contrary to the finding in other studies done worldwide ${ }^{1,2,13,14}$. The respondents perceived exclusive breastfeeding for six months to be the leading cause of MTCT. This misinformation is likely to discourage mothers not to breast feed their babies in poor resource countries where breastfeeding is important for child survival ${ }^{13-15}$.WHO and local guidelines for PMTCT recommends exclusive breastfeeding for 6 months, which has found to reduce infant mortality rate ${ }^{1,16,17}$. Counseling during antenatal care should emphasize the importance of exclusive breast feeding where formula feeding is not affordable. This study was done in peri-urban area where access to information and sensitization on HIV/AIDS through public and private media is accessible as well as routine counseling and testing during antenatal care.It is therefore difficult to conclude that the acquired knowledge was as a result of counselling done in the PHFs.

About half of the respondents were knowledgeable that MTCT may occur during pregnancy, this is similar to the finding in rural Nigeria where more than half of the pregnant women recognized pregnancy as the time during which MTCT occurs ${ }^{12}$. ARV s prophylaxis is a known preventive measures during pregnancy as well as during the infancy period. In order to get a generation which is free of HIV then specific strategies should be employed to ensure effective ARV coverage to the infants by bridging the knowledge gap among antenatal attendees shown in this study.

Timing of giving ARVs to HIV positive mothers for PMTCT was poor where $15.7 \%$ respondents did not know when to start prophylaxis. The current PMTCT guidelines ${ }^{16,17}$ emphasise the need for pregnant women to attend antenatal care in the first trimester and start ARVs prophylaxis when need arise.

High level of education, occupation and age were found to be significantly associated with high level of knowledge and positive attitude towards MTCT as it has been documented in other studies ${ }^{11,12,18,19}$. Marital status proved not to have any relationship with level of knowledge on PMTCT.

Being HIV positive was found to have an increase in the knowledge twice as much compared to HIV negative. Being HIV positive raises concerns about one's health and that of the unborn child. During post test counseling HIV positive pregnant women are given additional information on ARVs prophylaxis/treatment, counseling for infant feeding options, disclosure and partner testing and this call for more time a counselor spend with the client.

Majority of the respondents felt that it was important for pregnant women to be tested for HIV as this will help them to take protective actions against infecting their newborn ${ }^{6,20,21}$. Thirty three percent of the pregnant women responded that an HIV infected woman can get pregnant and have children. This shows that pregnant women are aware about available different strategies which are in place to ensure that HIV infected women can get children which are not infected thus preserving and enjoying fertility and reproduction as basic human rights ${ }^{22}$.

The knowledge on preventing oneself from acquiring HIV infection during pregnancy and breastfeeding (condom use) was low. This is similar to a study done by Leshabari et al which showed that $40 \%$ of the nursing women reported to practice safer $\operatorname{sex}^{23}$.Stigma and fear of disclosing result was mentioned to be barriers to implement the recommended period of exclusive breastfeeding and chosen mode of infant feeding.

The knowledge assessment in this study was done using closed ended questionnaire; this limited the participants from giving their view. Our study did not explore the time interval from counselling and testing to the time when the study was done which is important to reduce knowledge by recall bias. We also acknowledge the limi- 
tation that the study did not differentiate the knowledge level between the newly diagnosed HIV and those who are known HIV in treatment. Thus, the relatively high level of basic knowledge in our findings may be contributed by the study area (peri-urban) where access to information and sensitization on HIV/AIDS through public and private media is easily accessible.It is therefore difficult to conclude that the acquired knowledge was as a result of counselling done in the PHFs.

\section{Conclusion}

There is a knowledge gap among women attending ANC clinics on PMTCT of HIV in the PHFs in Tanzania. The knowledge on the important aspects of MTCT and its prevention was found to be inadequate according to this study. Knowledge on when transmission of mother to child of HIV occurs was adequate but the knowledge on preventive measures and timing of ARVs prophylaxis was unsatisfactory. This has an implication on reducing the pediatric HIV burden in the country. Women had positive attitude towards PMTCT interventions but probably the quality of counseling need to be reviewed and improved. This could be achieved through qualitative research.

\section{References}

1. De Cock KM, Fowler MG, Mercier E, de Vincenzi I, Saba J, Hoff E, Alnwick DJ, Rogers M,Shaffer N. Prevention of mother-to-child HIV transmission in resource-poor countries: translating research into policy and practice. JAMA, 2000; 283:1175-1182.

2. Report on the global AIDS epidemic. UNAIDS 2008

3. Dabis F. "Rate of Mother to Child Transmission of HIV 1 in Africa, America and Europe, results from perinatal studies". J. Acquired Immune Deficiency Syndrome; 1995; 8(5); 34-38.

4. Report on global AIDS epidemic. UNAIDS 2010

5. Townsend CL,Cortina-Borja M,Peckham CS,de Ruiter A,Lyall H,Tookey PA. Low rates of mother-tochild transmission of HIV following effective pregnancy interventions in the United Kingdom and Ireland, 2000-2006. AIDS. 2008; 22:973-981.

6. Newell ML. Current issues in the prevention of mother-to-child transmission of HIV-1 infection. Trans R Soc Trop Med Hyg, 2006; 100:1-5.

7. Tanzania National PMTCT guidelines. Ministry of Health and Social Welfare 2007.

8. UNGASS country progress report Tanzania Mainland. Dar es Salaam. Tanzania Commission for AIDS.
2008.

9. Sennen HH, Hélène C, Neil JH. Resource Center for Adolescent Pregnancy Prevention (ReCAPP): Theories and Approaches: Health Belief Model.Towards an understanding of barriers to condom use in rural Benin using the Health Belief Model: A cross sectional survey. BMC Public Health.2005;5:8.

10. Behailu M, Adebola AA. Effectiveness of interventions to prevent mother-To-child transmission of HIV in Southern Ethiopia. International Journal of Women's Health.2011;3 359-366

11. Eli FF, Thorkild T, Marina M, Rachel M, Ingunn MSE. Mothers' Knowledge and utilization of prevention of mother to child transmission services in northern Tanzania. Journal of the International AIDS Society.2010;13:36

12. Moses OA,Munir'deen A, Peter A. Awareness and Knowledge of MTCT of HIV among pregnant women attending a federal medical center in Nigeria. Journal of National Medical Association.2007; 99 (7); 758-763.

13. WHO. Effect of breast feeding on infant and child mortality due to infectious diseases in least developed countries: a pooled analysis. Collaborative Team on the role of breast feeding on the prevention of infant mortality. Lancet.2000; 355: 451-5.

14. World Health Organization Anti-retroviral drugs for treating pregnant women and preventing HIV infections in infants in resource limited settings: Towards universal access: recommendation for a public health approach. Geneva, Switzerland: World Health Organization. 2006. Available from URLhttp://www.who.int/reproductivehealth/publications/rtis/9241594667/en/ index.html Accessed January18, 2012

15. Karl P, Motlatso GM, Khanyisa P Infant-feeding practices and associated factors of HIV-positive mothers at Gert Sibande, South Africa. Acta Padiatrica. 2011; 100,538-542

16. Andrea LC, Freddy P, Matthews M, Jennifer C, Barbara E, Jo Keatinge, Rochelle, PW, Angela M,Rumbidzai M, Francois D, Kenneth AF. WHO Guidelines for Prevention of Mother-to-Child HIV Transmission in Zimbabwe: Modeling Clinical Outcomes in Infants and Mothers. PLoS ONE .2010 www.plosone.org/accessed on January 18, 2012

17. Tanzania National PMTCT Refresher Training Module 1: May 2011

18. Anne-Cécile ZB, Irène EY, Franscisca M,Guillaume C, Linda A,SamuelAA, Catherine L,Alfred KN, Walinjom FTM. Knowledge of Pregnant Women on Mother-toChild Transmission of HIV in Yaoundé. The Open AIDS 
Journal. 2011; 5, 25-28

19. Leshabari SC, Astrid B, de Paoli M,Karen MM. HIV and infant feeding counselling: challenges faced by nurse-counsellors in northern Tanzania. Human Resources for Health 2007, 5:18

20. Nguy $\square$ nT'T, H $\square$ nh L, Tine MG, Vibeke R Number and timing of antenatal HIV testing: Evidence from a community-based study in Northern Vietnam. BMC Public Health.2011;11:183

21. Mickey C, Tanya D, Debra J, Ann A. Preventing HIV transmission to children: quality of counseling of mothers in South Africa. Acta Padiatrica.2005; 94: 357363
22. Cooper ER, Charurat MML, Hanson IC, Pitt J, Diaz C, Hayani K, Handelsman E, Smeriglio V, Hoff R, Blattner W. Women and Infants' Transmission Study Group:Combination antiretroviral strategies for the treatment of pregnant HIV-1-infected women and prevention of perinatal HIV-1 transmission. J Acquire Immune Defic Syndr. 2002; 29:484-494

23. Leshabari SC, Koniz-Booher P, Astrom A, de Paoli AN, Moland KM. Translating global recommendations on HIV and infant feeding to the local context: the development of culturally sensitive counseling tools in the Kilimanjaro region, Tanzania. Implement Sci; 2006; 1: 22. 